\title{
Behavior Modification Applied to Requirements Engineering for Medical Applications
}

\author{
Gil Hernández-Ledesma ${ }^{1}$, Noé Hernández-Ledesma ${ }^{2}$ Erik G. Ramos ${ }^{3}$, \\ Carlos A. Fernández-y-Fernández ${ }^{3}$ \\ ${ }^{1}$ Universidad Tecnológica de la Mixteca, Ingeniería en Computación, Huajuapan de León, \\ Oaxaca, Mexico \\ ${ }^{2}$ Universidad Regional del Sur Este, Licenciatura en Psicología, Oaxaca de Juárez, \\ Oaxaca, Mexico \\ ${ }^{3}$ Universidad Tecnológica de la Mixteca, Instituto de Computación, Huajuapan de León, \\ Oaxaca, Mexico \\ hernandezlg1f@gmail.com, herled23@gmail.com, \{erik,caff $\} @$ mixteco.utm.mx
}

\begin{abstract}
This paper shows a development practice for the requirements process of a medical application. In this process, a psychology specialist was included in order to improve the application from the specification of requirements, considering subjects such as: support networks, behavior modification, increased intrinsic and extrinsic motivation and the creation of tools to facilitate patientphysician communication. This resulted in 11 new requirements. When a psychology specialist is involved in the requirements process, a new perspective on the patient is obtained, one that is broader than the requirements engineer usually has. It considers human needs that can serve to stimulate the user to avoid certain negative behaviors or to encourage positive behaviors. One of the main objectives of an application that helps a patient in their medical treatment is that the user does not abandon it, and the psychological perspective created requirements may help in this.
\end{abstract}

Keywords: requirements engineering, support networks, intrinsic and extrinsic motivation, behavior modification techniques.

\section{Introduction}

This paper presents a practice in which a psychological approach was used to develop the requirements process. It was defined with the Essence specification [1], a standard approved by the Object Management Group. This practice was applied to obtain the requirements of a web application (the second component of the Hippocrates system).

The World Health Organization (WHO) indicates that Mexico holds first place in obese and overweight children and second place in adults [2]. 
According to data from INEGI (Instituto Nacional de Estadística y Geografía) during 2014, the primary cause of death in Mexico was heart disease, with a total of 121,427 deaths; diabetes mellitus is the second greatest cause of death with 94,029 deaths, while in sixth place is stroke with 33,166 deaths [3].

Hippocrates will be a system to help control people's feeding habits, and will emphasize their physical activity and their rehabilitation, including a smart assistant planner with detailed dieting habits for a patient with high cholesterol and triglyceride problems.

Hippocrates components will be:

1st component: A module that works with Microsoft Kinect, which will help patients with a painful hemiplegic shoulder.

2nd component: A web module that will help patients keep an accurate record of what they eat and the physical activity they perform thus facilitating and improving the analysis of the nutritionist.

3rd component: The previous module will be complemented with a component that encourages physical exercise.

4th component: A smart assistant that helps create diets for people with cholesterol and triglyceride problems.

To obtain the user stories and product backlog [4], interviews and brainstorms were used with the users and client. According to [5], a first product backlog was obtained, and later a psychology specialist analyzed and suggested changes in the user stories. A meeting was held to analyze and complete the first product backlog with the requirements engineer, the users and the client.

The psychology specialist suggested improvements in the user stories to encourage and increase the patients' affinity to their treatment process, such as:

- Support networks: A set of emotionally meaningful people with a sense of community, not necessarily linked to a blood bond that provides social support [6], to facilitate the patient in the therapy process in order to avoid relapses or alienation in treatment, adding meaning to treatment and a feeling of commitment to their health.

- Tools to facilitate patient-physician communication: The aim is to improve communication through the implementation of codes shared between patient and physician for the transmission of messages, highlighting the information processed by the patient, helping to understand the treatment and converting the process into something lighter and personalized [7].

- Behavior modification techniques: These techniques will be used in order to encourage, reinforce or eliminate certain behaviors in order to reach the target behavior that will have as a consequence adherence to treatment. Among the behavioral principles are: positive reinforcement, generalization and self-control [8] [9].

- Increased intrinsic and extrinsic motivation: Based on support networks and behavior modification, it will modify the levels of motivation in the patient, in order to increase the treatment adherence even with a long-term treatment [10]. 
The consideration and implementation of the elements reviewed above results in an increase in adherence to treatment through the knowledge of their health status, their identification as a patient and the responsibility that this has with itself.

The remainder of this paper is organized as follows: In section two, important works related to the application of psychology in the requirements engineering are presented; Section three presents the development of the requirements process for the second module of the Hippocrates system which will help patients keep an accurate record of what they eat and the physical activity they perform; Section four discusses the proposed practice; In section five, the proposed new requirements are presented by the analysis of the psychology specialist. The final section reports the conclusions and propose some future work.

\section{Related Work}

\subsection{User-Centered Design (UCD)}

The UCD is a methodology that considers human factors and ergonomics for the design of computer systems, and has been used in a wide variety of projects: in geoinformation technologies [11]; the redesign of an electronic health record with drugdrug interactivity alerts (the system redesigned with UCD improved effectiveness and efficiency) [12]; for the development of an effective tool for rehabilitation using serious games [13]; development of assistive technology for disable and aged with an emphasis on the visually impaired [14]; a prototype for help deaf youths learning English [15].

The latter examples show that the UCD has been used in medical systems as systems like these need to be developed focusing on the needs of the patient or physician (users).

\subsection{Requirements Engineering, Human Factors and the Psychology of People}

In [16], review the work of programming psychology in five paradigms: 1) individual differences, 2) group behavior, 3) organizational behavior, 4) human factors, and 5) cognitive science, to determine how the programmer behaves when influenced by certain factors. This is done in such a way that seeks, for example, the characteristics necessary for a good programmer.

Ergonomics and human factors is an area closely related to psychology. Authors such as [17] emphasize the importance of human factors in software development because they define this as a technical and human process as development teams generate technological solutions, interact, discuss and work together. A recurrent theme is the design of systems that contemplate phenomena studied intimately by psychology: anxiety and assertiveness [18].

Other works [16] present the importance of the relationship between the development of computational systems and human cognition, generating interdisciplinary branches such as cognitive engineering that considers the modification of environmental demands by modifications in the interaction with technology presented in work environments. 
There are papers that evaluate the relationships that are established between the development teams of an application and the users or clients. In [19] sentimental, social and political conditions are analyzed in the requirements process, so that the requirements engineers can handle and interact with the psychology of the people.

In [20] a cognitive engineering technique is used: concept mapping, to convert information provided by users into software requirements. This technique is applied to a case study, namely, through assisting development of a system for the Air Force's Alaskan Air Command.

Similarly, in [21], the relationship between personal values and the requirements of two medical systems through psychology are analyzed.

PERE (Process Engineering in Requirements Engineering) [22] is a tool that analyzes interconnected process components to adapt techniques to the requirements process while conducting an analysis of the human factors of those involved in development.

\subsection{Calorie Counter Apps}

There are similar systems to the second component of Hippocrates, most of which focus on the calorie counts of users when consuming food and doing exercise. For example, the website Fatsecret [23] in addition to having the two aforementioned functions, it has a catalog of healthy recipes.

This site has some functionalities with the same objective of our application and this paper. For example, Fatsecret has a community in which you can share what you eat. The system also sends you an email to remind you to verify your weight, as aversive reinforcement. Other applications of this type are: MyFitnessPal [24], MyPlate [25] and EasyFit [26].

On the other hand, there are systems completely focused on monitoring your physical activity. For example: Runtastic [27] monitors and measures your training with the GPS of your smart phone when performing activities like: running, cycling or walking. You get statistics such as distance traveled and calories burned. Some other examples of this type of applications are Google Fit [28] and EasyPedeometer [29].

\section{Methodology}

The work presented uses a different approach from that of related work, because in the papers cited, the focus is on the human factors and the psychological background of the requirements engineer and the stakeholders to take advantage of them in the development of the application. Our work considers a part of psychology to create an application that helps modify the behavior of the patient in order to reduce the factors that hinder treatment adherence.

The methodology used is divided into two stages: in the first stage the product backlog was generated after interviewing the users. In this way, the system's functionalities were obtained. In the second stage, the psychology specialist analyzed and began to improve the product backlog with the aforementioned objective. 


\subsection{First Stage}

To obtain the first version of the product backlog, five users were interviewed:

- User \#1: The user has used applications similar to the second component of the Hippocrates system, undergone weight reduction treatments with the help of nutritionists and diets and performs daily exercise. Age: 25 years.

- User \#2: The user has undergone weight reduction treatments with nutritionists and diets. Age: 42 years.

- User \#3: The user has had diabetes for 32 years, and follows a diet with a nutritionist, performs daily exercise and uses insulin. Age: senior citizen.

- User \#4: The user has triglyceride problems; he does not have constant advice from a nutritionist. Age: 46 years.

- User \#5: The user has reduced his weight only with physical activity. Age: 20 years.

Two techniques were used to obtain the user stories: interviews and brainstorming [5] in three meetings, then the requirements engineer generated the first version of the product backlog. Poker planning was used to calculate the effort of the product backlog. Poker planning was used to calculate the effort to create the application.

\subsection{Second Stage: Psychology Intervention in the Requirements Process}

The specialist in psychology departed from the general objective of the application specified by the requirements engineer and the product backlog, and began to identify needs and characteristics of the patients, which, in turn, were used to propose requirements that facilitate the development of the skills and behaviors involved in treatment.

The following topics were considered: support networks, motivation and emotions, framing effect (experiences, beliefs, myths, education, sociocultural context), treatment adherence and the human communication process. The specialist was free to suggest new requirements.

Another factor considered was the balance of personal needs involving environmental conditions, family development and social circles in order to optimize and take advantage of these elements to accompany the patient in treatment.

The psychology specialist performs an Applied Behavior Analysis (ABA) considering the Antecedent-Behavior-Consequence (ABC) of the Skinner paradigm [9] to identify possible environmental elements of users, behaviors produced (adaptive or maladaptive) and positive and aversive stimulus.

The effort required for the creation of the application was calculated again considering the new user stories. The engineer, the client, a user and the psychology specialist reviewed this new version of the product backlog. The following section defines the proposed practice. 


\section{Proposed Practice: Behavior Modification Applied to Requirements Engineering for Medical Applications}

Table 1, defines the practice so that it can be replicated. The practice was defined following the Essence specification [1], a standard approved by the Object Management Group. In particular, the KUALI-BEH Kernel Extension of Essence was used, which allows to define practices independently of the technology, size and life cycle of the project to be applied by other practitioners.

\section{$5 \quad$ Results}

\subsection{Initial Requirements Considering Psychological Factors}

The assessment of the psychology specialist found that some of the user stories created by the requirements engineer considered some of the psychological factors mentioned above.

Communication difficulties: patient-physician. Constant and prolonged out-ofoffice communication.

Advantages. It will increase the feeling of patient safety by continuous communication compared to a non-immediate communication.

Requirements.

- A daily log of the patient's feed will be displayed.

- A daily record of the exercises performed by the patient will be kept, so that they can be added, deleted or edited.

- A daily log of the exercises performed by the patient will be displayed.

- Information such as waist size, weight, cholesterol or glucose of the patient can be added, deleted or edited and statistics will be generated with this information.

Table 1. Practice: Behavior modification applied to requirements engineering for medical applications.

\begin{tabular}{|c|c|}
\hline BehaviorModificationToRequirementProcess & Practice \\
\hline \multicolumn{2}{|l|}{ Behavior modification applied to requirements engineering for medical applications. } \\
\hline \multicolumn{2}{|c|}{$\begin{array}{l}\text { Objective. Use behavior modification to create user stories that help decrease the factors that encourage } \\
\text { patients to abandon their medical treatment and create a product backlog. }\end{array}$} \\
\hline \multicolumn{2}{|l|}{$\begin{array}{l}\text { Entry: Conditions. Users and a psychology specialist should be ready to attend meetings. } \\
\text { Result: Work Products. Product backlog. } \\
\text { Conditions. The team will agree on possible variations in the effort to develop the application. }\end{array}$} \\
\hline \multicolumn{2}{|c|}{$\begin{array}{l}\text { Completion Criteria: The users, the client and the requirements engineer must approve the possible } \\
\text { variation in the effort to develop the application. }\end{array}$} \\
\hline \multicolumn{2}{|l|}{ Guide } \\
\hline \multicolumn{2}{|c|}{$\begin{array}{l}\text { Activity } 1 . \text { The requirements engineer meets with users to create user stories and methods such as } \\
\text { interviews and brainstorming are used to obtain an initial version of the product backlog. }\end{array}$} \\
\hline & \\
\hline
\end{tabular}


Competences: The person who creates the product backlog must have knowledge of requirements engineering. Measures: None

Activity 2. Poker planning is used to calculate the effort of the user stories of the first product backlog. Input: Work products. First product backlog. Output: Work products: First product backlog with effort.

Competences: The person who creates the product backlog must have knowledge of poker planning. Measures: None

Activity 3. Contact psychology specialist with training in general psychology and specific knowledge of behaviorism and theory of motivation.

Input: None. Output: None

Competences: Psychology specialist must have knowledge of behaviorism and theory of motivation. Measures: None

Activity 4. The psychology specialist reviews the first version of the product backlog considering the objective of the system, expected behavioral modification (increase of target behaviors and decrease of maladaptive behaviors) and factors involved in the expected response.

Input: Work products. First product backlog. Output: None

Competences: None. Measures: None

Activity 5. The psychology specialist performs an Applied Behavior Analysis (ABA) considering the Antecedent-Behavior-Consequence (ABC) of Skinner paradigm to identify possible environmental elements of users, behaviors produced (adaptive or maladaptive) and positive and aversive stimulus, from this, new requirements are obtained to try improve the system.

Input: Work products: First product backlog. Output: Work products: Second product backlog.

Competences: The psychology specialist must have knowledge of user stories. Measures: None

Activity 6. Poker planning is used again to calculate the effort of the new user stories of this version of the product backlog.

Input: Work products: Second product backlog. Output: Work products: Second product backlog with effort.

Competences: The person who creates the product backlog must have knowledge of poker planning. Measures: None

Activity 7. The users, the client and the requirements engineer meet to analyze (approve and discard) the user stories proposed by the psychology specialist according to the increase of the time of development.

Input: Work products: Second product backlog with effort. Output: Work products: Second product backlog with effort and reviewed.

Competences: The person who creates the product backlog must have knowledge of requirements engineering. Measures: None

\subsection{Requirements Suggested by the Psychology Specialist}

\section{Low or Middle Levels of Education Attained}

Background. In studies related to treatment adherence, low or middle levels of education attained has been identified as a factor related to the difficulty of understanding the physician's instructions, awareness of their health status, general consequences of treatment failure, communication problems and difficulty gaining insight (awareness) [30].

- Suggestion \#1. Educate patients through multimedia (videos, texts, books, magazines, forums) of topics related to their illness. 
- Advantages: The system develops awareness of the benefits and consequences of patient treatment and illness.

- New requirements:

- Show videos and informative articles on the patient's home page related to the user's treatments and diseases.

\section{Lack of Awareness of the Disease}

Background. Another factor reviewed in [30] is ignorance on issues related to illness and health status, showing that concern about the repercussions on their daily lives is a factor that increases the index of treatment adherence.

- Suggestion \#2. Elimination of myths and false beliefs held about the disease.

- Advantages: Awareness is generated about the etiology of the disease and the mechanisms to address it in the right way.

- New requirements:

- Show videos and informative articles on the patient's home page related to the user's treatments and diseases.

○ The physician can add information to a FAQ section with general patient illness information.

- Suggestion \#3. Understanding treatment and prognosis: Explanation of the function of medications, dose ratio and times of progress or forecasts.

- Advantages: Awareness is generated about the treatment of the patient and their influence on their future.

- New requirements:

- The physician may add information related to the medicines commonly provided, such as drug reactions, contraindications and therapeutic use, this information will be shown to patients.

\section{Difficulty understanding the physician}

Background. Theory of human communication as a process where it is considered a symmetry and an agreement about the language, code, content and auxiliaries used to improve communication.

- Suggestion \#4. Charts for the interpretation of progress.

- Advantages. Improvement in the understanding of the patient through taking advantage of the ease of interpreting a figure versus a number.

- New requirements:

- Charts of calories consumed and weight forecasts.

$\circ$ Charts of patient conflation and morphology.

\section{Support from Other Patients}

Background. According to the thanatology (set of knowledge based on the significant losses of a person, object or status and the process of mourning subsequent to this), the support networks are identified as a determining factor for the continuation of daily activities, in this case, the treatment. 
- Suggestion \#5. Linkage with social networks among patients with the same disease to eliminate the low expectation of improvement.

- Advantages. Creation of support networks, generation of company feeling and commitment to treat the disease.

- New requirements:

○ Integration with the Facebook API.

\section{Professional Support}

Background. In this section, the same background of the sections was used: lack of awareness of the disease and low or middle levels of education attained [30].

- Suggestion \#6. Schedule of medical appointments and treatment by videoconference.

- Advantages. The patient can receive care from the physician anywhere with an internet connection.

- New requirements.

○ Functionality that allows scheduling appointments with the physician through the system.

- Suggestion \#7. Network of experts: Creation of a network of medical specialists for the treatment of the patient.

- Advantages. Physicians will improve patient care, as treatment will be complemented by the care of more specialists.

- New requirements.

○ Specialists from different areas can join to the system.

\section{Other Support Features}

- Suggestion \#8. A calendar.

- Advantages. This is a tool that will help in the constancy of the treatment.

- New requirements.

○ Calendar that helps the patient to remember upcoming events related to their treatment.

- Suggestion \#9. A reward system.

- Advantages. Helps maintain patient behavior because rewards are sequential and similar to activities.

- New requirements.

o Sequential achievement system, in which the patient is rewarded with badges. Messages with positive content (For example: Well done, you have been working for three days!) or maladaptive content (For example: You have not exercised for a week, right?).

Time estimates were obtained through Scrum planning poker to calculate the effort of the product backlog before and after the intervention of the psychology specialist. In the initial version of the product backlog, the effort was 208 hours, while in the new version the effort was 233 hours, which represents a 25 -hour increase $(12.01 \%$ of initial hours of effort). Because the new functionalities required little time and the gain in 
terms of functionality is significant, it was decided to include all the new requirements in the system.

The requirements defined in this paper are not definitive and will be adapted when the application is developed (agile approach).

\section{Conclusions and Future Work}

This work shows a new practice that unifies two areas: the psychology and engineering requirements for use in medical applications. When an expert in psychology was involved in the process of requirements, a product backlog was generated and considered aspects of users ignored by the requirements engineer in relation to support networks, behavior modification techniques, and increases of intrinsic and extrinsic motivation.

With a psychology specialist, the user is seen from a broader perspective in terms of the understanding of human needs. In this way, this approach considers factors involved in activating the cognitive processes necessary for any interactive activity. The specialist involved not only provides knowledge regarding behavioral and observable issues, he also provides the opportunity for the prediction of possible responses to certain stimuli offered by the requirements engineers before designing such requirements, an alternative to saving effort.

The requirements can be universalized o adapted for a specific population or culture giving a variety in the breadth or reach in the system. From this new specification, an application will be designed that will offer functionalities that will meet the operational needs of the users, while taking into consideration psychological factors involved in the treatment, which can result in health benefits.

Likewise, user stories were obtained to establish channels of communication and understanding between the patient and the physician. The goal of an application is to solve a problem or automate a process. In the case of a medical application that will help patients follow a medical treatment, one of the main objectives is that the user does not leave this treatment. According to the above, the application must be designed to take this into consideration. The development time added in this case is insignificant when considering the user stories added.

Future work would involve the design and development of this component of the Hippocrates system using the requirements expressed in this paper, the implementation of this approach for the design and development of software for other areas, the inclusion and design of systems considering patients with psychological illnesses, such as depression and a more complete validation.

\section{References}

1. OMG: Essence kernel and language for software engineering methods. http://www.omg.org/spec/Essence (2015)

2. Gutiérrez-Pulido, H., Mariscal-González, M., Almanzor-García, P., Ayala-Dávila, M., Gamba-Hernández, V., Lara-Garzón, G.: Diez problemas de la población de Jalisco: Una 
perspectiva socio demográfica. $1^{\text {st }}$ edn., Gobierno de Jalisco, Secretaría General de Gobierno, Guadalajara Jalisco México (2011)

3. INEGI: Principales causas de mortalidad por residencia habitual, grupos de edad y sexo del fallecido. Available at: http://www.inegi.org.mx/est/contenidos/proyectos/ registros/vitales/mortalidad/ tabulados/ConsultaMortalidad.asp (2014)

4. Schwaber, K.: Agile project management with Scrum. $1^{\text {st }}$ edn., Microsoft press (2004)

5. Lethbridge, T., Laganiere, R.: Object-Oriented Software Engineering: Practical Software Development Using UML and Java. $1^{\text {st }}$ edn., McGraw-Hill, Inc., New York, NY, USA (2002)

6. Anaya, N. C.: Diccionario de psicología. Ecoe Ediciones (2004)

7. Watzlawick, P., Beavin, H., Jackson, D. D.: Teoría de la comunicación humana: interacciones, patologías y paradojas. $1^{\text {st }}$ edn., Herder, Barcelona (1974)

8. Martín, G., Pear, J.: Modificación de conducta ¿Qué es y cómo aplicarla? $5^{\text {th }}$ edn., Prentice Hall, España (1996)

9. Stumphauzer, J. S.: Terapia conductual: manual de entrenamiento para psicologos, medicos, enfermeras, trabajadores sociales, pedagogos, maestros. Trillas (1983)

10. Marshall, J.: Motivación y emoción. $5^{\text {th }}$ edn., Mcgraw-hill Interamericana (2010)

11. Fuhrmann, S.: User-centered design for geoinformation technologies. Comprehensive Geographic Information Systems, Elsevier, Oxford (2017)

12. Luna, D. R., Lede, D. A. R., Otero, C. M., Risk, M. R., de Quirós, F. G. B.: Usercentered design improves the usability of drug-drug interaction alerts: Experimental comparison of interfaces. Journal of Biomedical Informatics, 66, pp. 204-213 (2017)

13. Elnaggar, A., Reichardt, D.: Digitizing the Hand Rehabilitation Using Serious Games Methodology with User-Centered Design Approach. In: 2016 International Conference on Computational Science and Computational Intelligence (CSCI), pp. 13-22 (2016)

14. Nayak, S. K., Chavan, N. S., Srinath, N.: User centered inclusive design for assistive technology. In: 2016 IEEE Annual India Conference (INDICON), pp. 1-6 (2016)

15. Anindhita, V., Lestari, D. P.: Designing interaction for deaf youths by using usercentered design approach. In: 2016 International Conference on Advanced Informatics: Concepts, Theory and Application (ICAICTA), pp. 1-6 (2016)

16. Helander, M. G.: Handbook of human-computer interaction. Elsevier (2014)

17. Capretz, L. F.: Bringing the human factor to software engineering. IEEE software, 31(2), pp. 104-104 (2014)

18. Gannon, J. D.: Human factors in software engineering. Computer, 12, pp. 6-7 (1979)

19. Sutcliffe, A., Thew, S.: Analysing "people" problems in requirements engineering. In: 2010 ACM/IEEE 32nd International Conference on Software Engineering, 2, pp. 469470 (2010)

20. Lind, S., Marshak, W.: Cognitive engineering computer interfaces. I. Knowledge acquisition in the design process. In: Aerospace and Electronics Conference, NAECON, Proceedings of the IEEE 1994 National, 2, pp. 753-755 (1994)

21. Proynova, R., Paech, B., Koch, S. H., Wicht, A., Wetter, T.: Investigating the influence of personal values on requirements for health care information systems. In: Proceedings of the 3rd Workshop on Software Engineering in Health Care, SEHC '11, ACM, New York, NY, USA, pp. 48-55 (2011)

22. Viller, S. A.: Human factors in requirements engineering: a method for improving requirements processes for the development of dependable systems. Ph.D. thesis, Lancaster University, UK, available at: http://eprints.lancs.ac.uk/11686 (1999)

23. FatSecret: Fatsecret. Available at: https://www.fatsecret.com.mx (2017)

24. MyFitnessPal: Myfitnesspal. Available at: https://www.myfitnesspal.es (2017) 
Gil Hernández-Ledesma, Noé Hernández-Ledesma, Erik G. Ramos, Carlos A. Fernández-y-Fernández

25. Leaf-Group-Ltd: Myplate. Available at: http://www.livestrong.com/myplate (2017)

26. Hanna, M.: Easy fit. Available at: http://easyfit-caloriecounter.de/index.html (2017)

27. Runtastic GmbH: Runtastic.com tu comunidad de salud y fitness. Available at: https:// www.runtastic.com/es/ (2017)

28. Alphabet-Inc.: Google fit. Available at: https://www.google.com/fit/ (2017)

29. Hanna, M.: Contador de pasos - podómetro. Available at: https://play.google.com/ store/apps/details?id=easypedeometer.herzberg.com.stepcounter (2017)

30. Pfizer: La adherencia al tratamiento: Cumplimiento y constancia para mejorar la calidad de vida (2009) 